\title{
X-ray computed micro-tomography of reticulated vitreous carbon
}

\author{
Luis F. Arenas ${ }^{\mathrm{a}}$, Richard P. Boardman ${ }^{\mathrm{b}}$, Carlos Ponce de León ${ }^{\mathrm{a}, 1}$, Frank C. Walsh ${ }^{\mathrm{a}, 2}$ \\ a Electrochemical Engineering Laboratory, Department of Mechanical Engineering, Faculty \\ of Engineering and the Environment, University of Southampton SO17 1BK, UK. \\ ${ }^{\mathrm{b}} \mu$-VIS X-ray Imaging Centre, Faculty of Engineering and the Environment, University of \\ Southampton SO17 1BK, UK.
}

\begin{abstract}
The 3D structure of various grades of reticulated vitreous carbon (RVC) is studied by X-ray computed micro-tomography $(\mu \mathrm{CT})$. The settings required to estimate the bulk volumetric surface area accurately are investigated and the results are compared to those obtained from scanning electron microscopy and from pressure drop measurements via the Ergun equation. A resolution of $1.3 \mu \mathrm{m}$ per voxel in $\mu \mathrm{CT}$ imaging is needed to determine the volumetric surface area, but its value is highly dependent on post-processing. A resolution of $9.6 \mu \mathrm{m}$ per voxel underestimated the volumetric surface area, $A_{e}$, by a factor of up to 0.64 due to an incomplete resolution of the cell struts. This latter resolution is, however, sufficient to establish the volumetric porosity and the relative density. Theoretical estimations of electrical resistivity using these properties are consistent with those reported in the literature. Cell volume and cell surface area distributions are then obtained from computational analysis of the digitally rendered structure of 100 ppi RVC. Both cases can be approximated by a gamma function. Suitable instrumental $\mu \mathrm{CT}$ conditions for performing metrological studies on bare and modified RVC are proposed. Opportunities for the modelling of decorated and coated digitally rendered RVC are discussed.
\end{abstract}

\section{Graphical abstract}

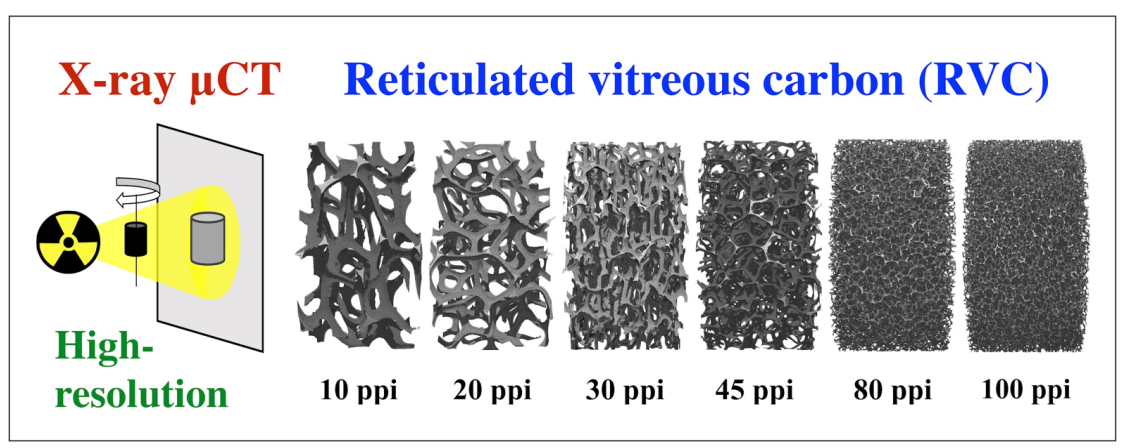
${ }^{1}$ Author for correspondence: Tel: +44 (023) 8059 8931, Email: capla@soton.ac.uk (C. Ponce de León)
${ }^{2}$ Author for correspondence: Tel: +44 (023) 8059 8752, Email: 1 .C.Walsh@soton.ac.uk (F.C. Walsh) 


\section{Introduction}

Reticulated vitreous carbon (RVC) is open-cell solid material produced by the controlled carbonization of a polymer foam infused with a polymerizable resin [1]. Due to its electrical conductivity, it is often employed as a high surface area porous electrode in electrochemical applications. With volumetric porosities up to $97 \%$, it is especially advantageous in electrochemical flow cells, from amperometric micro-sensors [2] to relatively large reactors [3-5]. Its hydraulic permeability is higher than carbon felt electrodes, which is useful when dealing with viscous electrolytes [6] or high solution velocities. RVC is self-standing and mechanically rigid [7], and has good chemical stability, offering a suitable 3D substrate for many types of functional surface coatings [8] and active materials [9]. Other uses of RVC are found in thermal management [10] and acoustical/vibrational insulation [11].

Following our recent review on the characteristics of RVC and its applications in the field of electrochemistry [1], we now turn our attention to analyse the RVC structure and physical properties by X-ray computed micro-tomography $(\mu \mathrm{CT})$. The present study builds on the early work by Friedrich [12], who obtained coarse 3D reconstructions of RVC at a time when $\mu \mathrm{CT}$ resolution was poor and computational power was limited. $\mu \mathrm{CT}$ is now a powerful tool for the characterization of porous materials [13]. This non-destructive technique can reveal the macro-, meso- and microstructures of highly complex three-dimensional matrices as well as their superficial morphology and related chemical composition (from local density). The subsequent computational analysis of the rendered digital $\mu \mathrm{CT}$ object permits to quantify structural properties [14], such as volumetric porosity (open and total), surface area, wall thickness, anisotropy, sphericity, average cell diameter, cell size distribution, 
cell volume distribution and tortuosity. Moreover, finite element meshes can be generated from the specimen's structure, enabling the modelling of electrical conductivity [15], mechanical [16] and thermal flow properties [17,18] of the foams. Likewise, 3D-printing now permits the manufacture of scaled up physical reproductions and structural analogues in different compositions of rendered digital objects [19].

X-ray settings, filtration, instrumental conditions and the resulting voxel (threedimensional discrete element) resolution are, however, critical to the production of accurate structural and dimensional data [20]. High spatial resolution relative to the studied features is essential, in addition to reasonable computational processing times. Furthermore, noise levels and beam hardening artefacts must be minimized by adequate filtration [20] as well as photon starvation effects caused when X-rays transverse a large path length relative to the mean path length for a given angle [21]. High resolution $\mu \mathrm{CT}$ imaging of porous metal and carbon foams is currently limited to small samples where differences among the beam path longitude are not significant. RVC poses the additional challenges of a low atomic number of carbon and a highly open network pore structure.

In electrochemical applications, the surface area per unit volume, $A_{e}$, of a porous electrode has critical importance due to its direct relationship to the current density and overall reaction rate. In addition to the convenience of structural imaging, we have acquired surface area data from $\mu \mathrm{CT}$ scans and considered the voxel resolution and $\mathrm{X}$ ray settings needed for obtaining values consistent with previous experimental work, including direct geometrical measurements on scanning electron microscopy (SEM) 
images [22], and the pressure drop, $\Delta P$, experienced by a liquid flowing though the porous medium within a rectangular channel of length $L$ [3]. In this case, the Ergun equation (1), yields the empirical constants $M$ and $N$ representing the turbulent and inertial forces, respectively, as a function of mean linear flow velocity, $v$ :

$$
\frac{\Delta P}{L}=M v^{2}+N v
$$

$A_{e}$ is then related to these constants through the following expression for fluid flow through packed beds [3]:

$$
\left(\frac{A_{e}}{1-\varepsilon}\right)^{4}=\frac{N^{3}(0.096 L \widetilde{\rho})^{2}}{M^{2}(5 L \gamma \mu)^{3}} \frac{\varepsilon^{3}}{(1-\varepsilon)^{4}}
$$

Where $\tilde{\rho}$ is the density of the fluid, $\mu$ its dynamic viscosity, and $\gamma$ the circularity factor of the pores.

\section{Experimental details}

\subsection{RVC specimens}

RVC samples grade 10, 20, 30, 45, 80 and 100 nominal pores per linear inch (ppi) were sourced from ERG Materials and Aerospace Corp (USA). The classical precursor for this material is polyurethane foam saturated with furfuryl alcohol $[23,24]$, which is polymerized with the aid of a catalyst at a moderately high temperature and then carbonized at over $1000^{\circ} \mathrm{C}$. For $\mu \mathrm{CT}$ scans, specimens of $15.0 \mathrm{~mm}$ diameter and 13.0 mm height were cut, see Figure 1a), except for 80 ppi grade, which had a height of 6.0 $\mathrm{mm}$. The specimens were fixed inside an acrylic polymer tube during the $\mu \mathrm{CT}$ scan. 
Porosity and surface area data were obtained from a cylindrical region of interest (ROI) with diameter of $12.0 \mathrm{~mm}$ and heights of $12.0 \mathrm{~mm}$, except for 80 ppi grade, which had a height of $5.0 \mathrm{~mm}$. To render structural images, a shorter ROI of $12.0 \mathrm{~mm}$ diameter and $5.0 \mathrm{~mm}$ height were used, see Figure 1b). Additionally, a smaller specimen of RVC 100 ppi (not shown) was machined in a lathe to $6.8 \mathrm{~mm}$ of diameter and $18.0 \mathrm{~mm}$ of height for a high-resolution scan. The ROI in this scan had a diameter of $2.66 \mathrm{~mm}$ and a height of $2.72 \mathrm{~mm}$. RVC was uncoated and cleaned with compressed air in all cases.

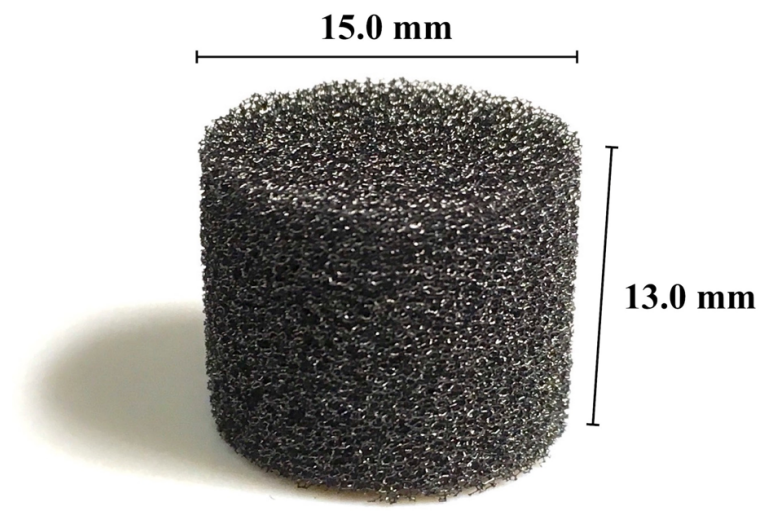

a) RVC specimen (100 ppi)

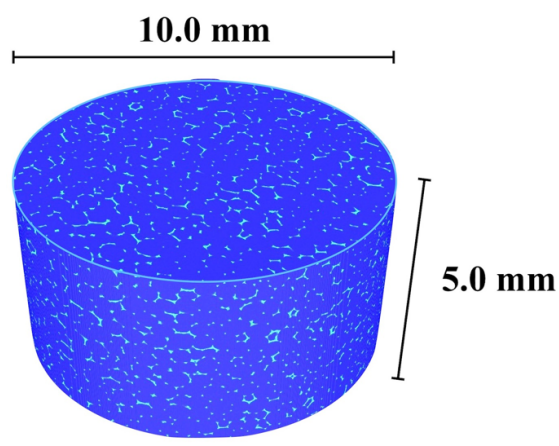

b) ROI for $\mu \mathrm{CT}$ image (100 ppi)

Figure 1. a) A specimen of 100 ppi RVC grade used for $\mu \mathrm{CT}$ at $9.6 \mu \mathrm{m}$ per voxel. b) The region of interest digitally cut from a $\mu \mathrm{CT}$ scan for structural imaging, showing cross sections of RVC struts and nodes. 


\subsection{Imaging techniques}

Scanning electron microscopy (SEM)

A JSM-6500F field emission electron microscope (Jeol Inc, USA) was used to obtain SEM images of uncoated $1 \mathrm{~cm}^{2} \mathrm{RVC}$ samples with a thickness of $5 \mathrm{~mm}$. The accelerating voltage was set to $10 \mathrm{kV}$ and sample-beam distances between $15 \mathrm{~mm}$ and $20 \mathrm{~mm}$ were used. Images were obtained with the main plane of the sample perpendicular in respect to the electron beam.

\section{$\underline{X \text {-ray computed micro-tomography }(\mu C T)}$}

Scans were performed for all RVC grades using the standard tungsten reflection target of a Nikon/X-Tek XTH 225 instrument, resulting in an isotropic resolution of $9.6 \mu \mathrm{m}$ per voxel. The detector used was a Perkin Elmer 1621, $2000 \times 2000$-pixel flat panel (isotropic pixels; size $200 \mu \mathrm{m} \times 200 \mu \mathrm{m}$ ) with a gadolinium oxysulphide scintillator. The X-ray peak voltage was $54 \mathrm{kV}$, with a current of $127 \mu \mathrm{A}$, and no filter was applied to the beam. Each scan consisted of 3142 projections with an analogue gain of $30 \mathrm{~dB}$, an individual frame exposure time of $1000 \mathrm{~ms}$, and two frames taken per projection. The distance from the X-ray source to the object was $36 \mathrm{~mm}$, and from the source to detector was $755 \mathrm{~mm}$. The resulting field of view was just over $19 \mathrm{~mm}$. Image files were extracted and analysed from $\mu \mathrm{CT}$ raw data using VG Studio MAX version 2.1 (Volume Graphics GmbH), employing the 'ISO50\%' value for thresholding [25].

In the case of the 100 ppi RVC, an additional high-resolution scan was performed with the $4 \times$ objective of the Zeiss Xradia 510 Versa X-ray microscope, yielding an isotropic resolution of $1.3 \mu \mathrm{m}$ per voxel. The camera pixel binning was set to $1 \times$, the $\mathrm{X}$-ray peak 
voltage was $50 \mathrm{kV}$ and the current was $80 \mu \mathrm{A}$, again with no filter being applied to the beam. The scan consisted of 3201 projections with an individual exposure time of 12 seconds. The distance from the source to the centre was $25 \mathrm{~mm}$ and $37.9 \mathrm{~mm}$ from the centre of the object to the detector. The resulting field of view was just under $2.7 \mathrm{~mm}$. For this sample, the post-processing and thresholding of the high-resolution $\mu \mathrm{CT}$ raw data was performed in Avizo 9.1 (ZIB and FEI SAS).

\section{Results and discussion}

\subsection{D structure of RVC}

The well-known structure of RVC consists of a three-dimensional network of quasipolyhedral cells interconnected by open 'windows', as shown in Figure 2a). Each cell is formed by vitreous carbon struts of trigonal cross section, which in most cases form tetrahedral nodes at their ends [26], giving mechanical rigidity to RVC. Strut edges display some undulations resulting from thermal shrinking during the thermal treatment step during RVC manufacture [1]. These features are shown in Figure 2b). $\mu \mathrm{CT}$ seems to reveal that the strut walls are denser than the internal material but it should be noted that the struts are usually not hollow; see [27]. This is a $\mu \mathrm{CT}$ artifact resulting due to the employed thresholding method, vide infra, in combination with the presence of densified walls due to curing of the precursor resin during manufacture. 


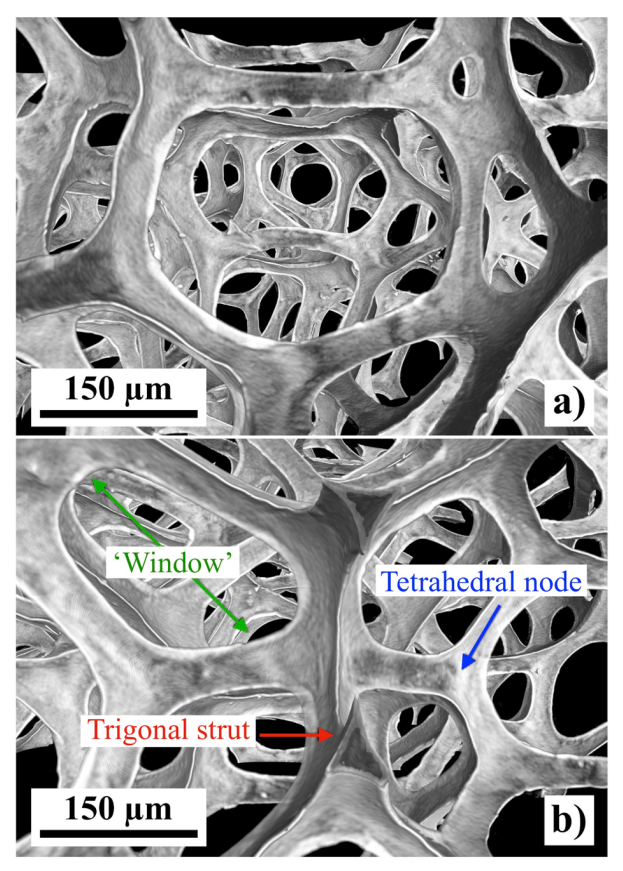

Figure 2. In-depth view of an X-ray computed micro-tomography of RVC 100 ppi with a resolution of $1.3 \mu \mathrm{m}$ per voxel and a thresholding of ISO50\%. a) A straightline path across multiple pores illustrates the open-cell structure. b) Trigonal struts, showing dense (but not hollow) vitrified walls and tetrahedral nodes.

Idealised open-cell foams have been compared to 3D tessellations of truncated octahedrons (Kelvin structure) and a combination of irregular dodecahedrons and tetrakaidecahedrons (Weaire-Phelan structure), which minimize the surface area of equal volume cells in space [28-30]. More complex aperiodic models have been considered, e.g., random Laguerre tessellations [31]. In reality, the structure of RVC is heterogeneous and aperiodic, with a distribution of cell shapes and cell sizes. Figure 3 shows a $0.5 \mathrm{~mm}$ slice of 100 ppi RVC. This image exemplifies the fine, open skeleton of RVC and displays the arrangement of the individual cells or 'bubbles' in the foam matrix. 


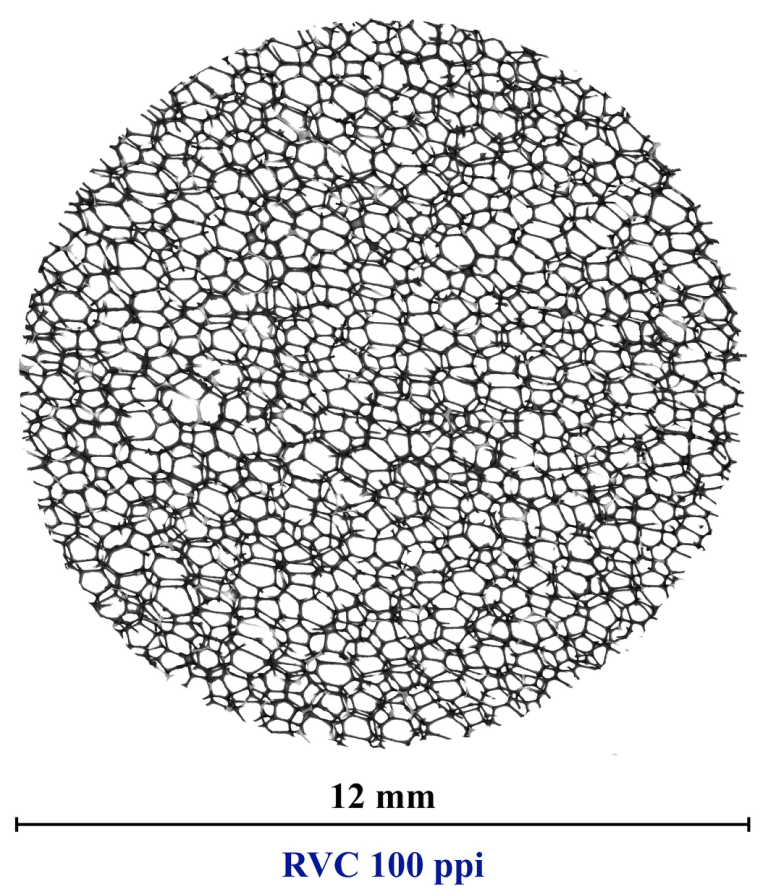

Figure 3. Frontal view of an X-ray computed micro-tomography 100 ppi RVC with a resolution of $9.6 \mu \mathrm{m}$ per voxel and a thresholding of $\mathrm{ISO} 50 \%$. The $3 \mathrm{D}$, uniform structure of this $0.5 \mathrm{~mm}$ thick slice of individual cells or 'bubbles' in the open foam is visible.

Representative SEM images of the studied RVC specimens are shown in Figure 4 and corroborate the structural features described above. Previously, similar SEM images were employed to determine the length, thickness and cross-section area of the struts as well as volumetric surface area [1,22]. SEM has been long used for the analysis of the RVC structure and the characterization of modified RVC surfaces, e.g., by metals [9], metal oxides [32], conductive polymers [33], polymer-ceramic composites [34] and carbon nanotubes [35]. 


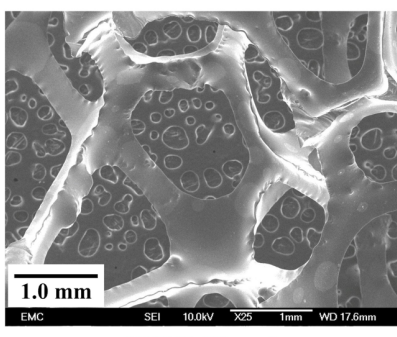

RVC 10 ppi

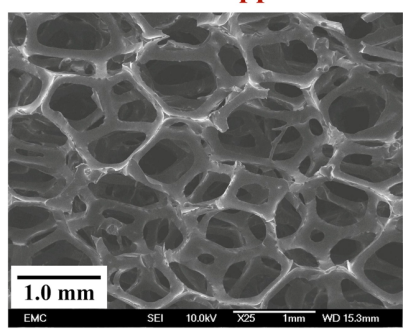

RVC 45 ppi

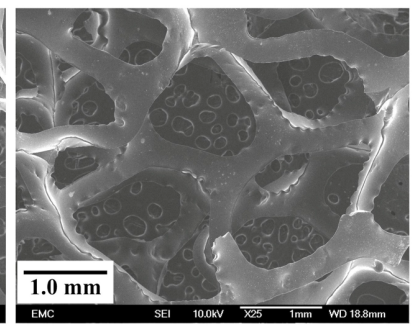

RVC 20 ppi

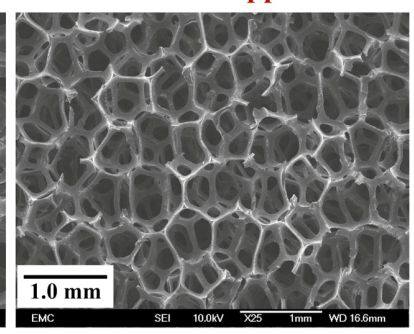

RVC 80 ppi

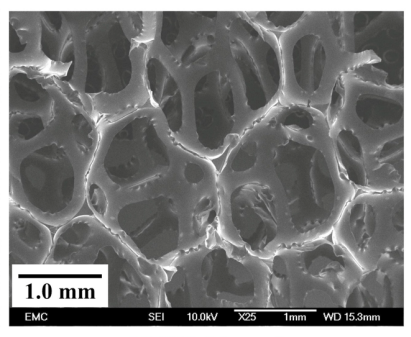

RVC 30 ppi

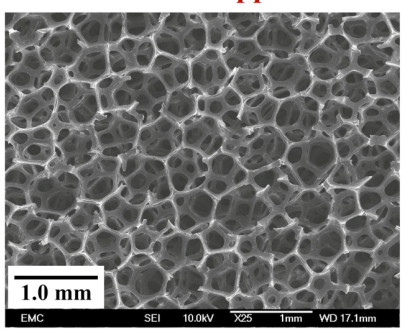

RVC 100 ppi

Figure 4. SEM images of RVC specimens, showing various available nominal pore per inch (ppi) grades. RVC is formed by a rigid network of open, interconnected cells. Conductive tape in the background of RVC 10 ppi and 20 ppi.

\subsection{The ppi porosity grade, cell dimensions and porosity}

Reconstructed $\mu \mathrm{CT}$ scans of the various grades of RVC are presented in projection and top view in Figure 5 and Figure 6, respectively. The structure of RVC has a high degree of homogeneity and is morphologically similar regardless of the porosity grade. As the number of nominal pores per linear inch, ppi increases, the average pore diameter decreases from $1.8 \mathrm{~mm}$ for 10 ppi RVC to $0.25 \mathrm{~mm}$ for $100 \mathrm{ppi} \mathrm{RVC}$, with dispersion ratios of approximately $0.2[1,22]$. Similarly, the average strut length reduces from about $1.3 \mathrm{~mm}$ for RVC 10 ppi to about $0.2 \mathrm{~mm}$ for RVC 100 ppi and the size of the individual windows interconnecting adjacent cells falls from about $2.1 \mathrm{~mm}^{2}$ for $10 \mathrm{ppi}$ RVC to less than $0.1 \mathrm{~mm}^{2}$ for 100 ppi RVC $[1,22]$. The smaller window sizes in higher ppi grades correspond to a significant increase in the volumetric surface area, $A_{e}$ and a simultaneous reduction of hydraulic permeability. 


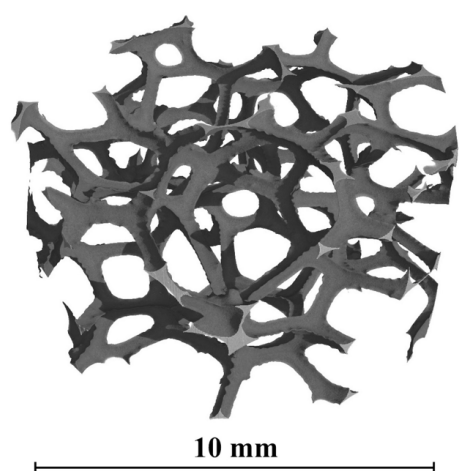

RVC 10 ppi
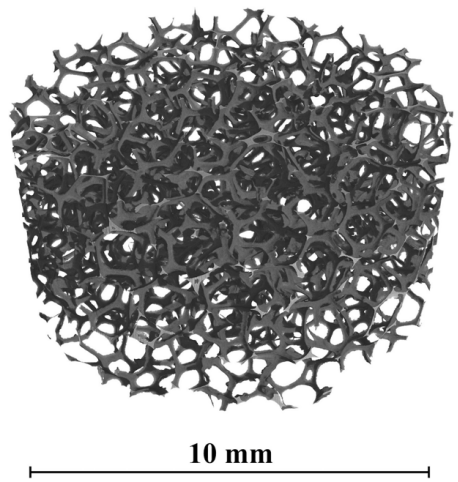

RVC 45 ppi

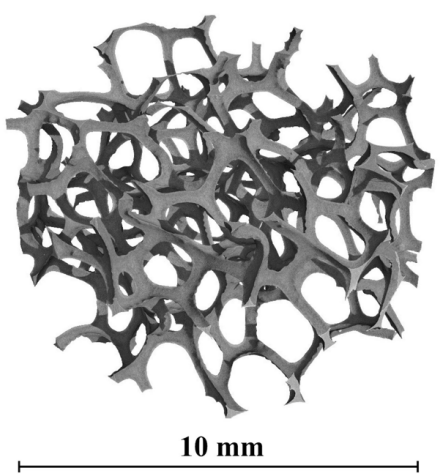

RVC 20 ppi

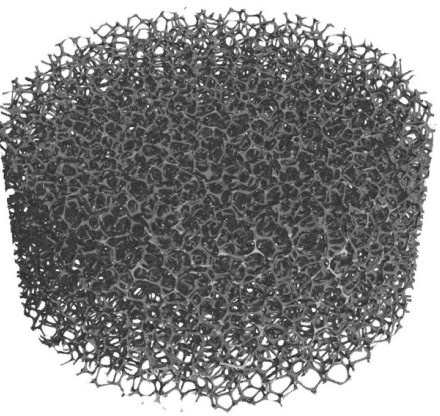

$10 \mathrm{~mm}$

RVC 80 ppi

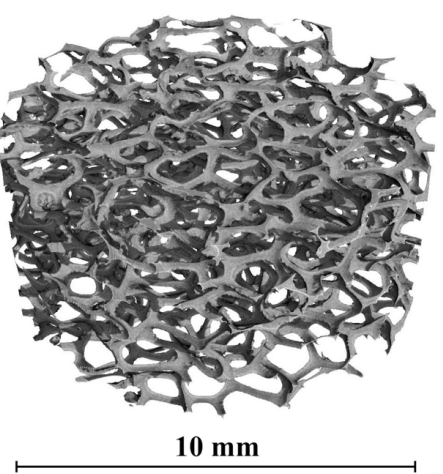

RVC 30 ppi

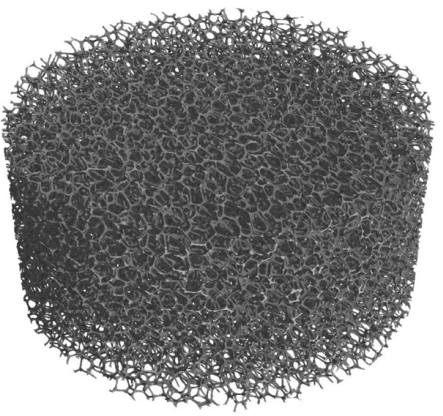

$10 \mathrm{~mm}$

RVC 100 ppi

Figure 5. Projection view of 3D-rendered CT scans of uncoated RVC samples, showing various ppi grades. The open structure of RVC is homogenous across different scales and highly porous. 


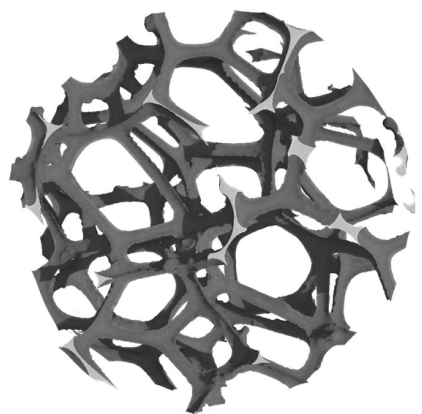

$10 \mathrm{~mm}$

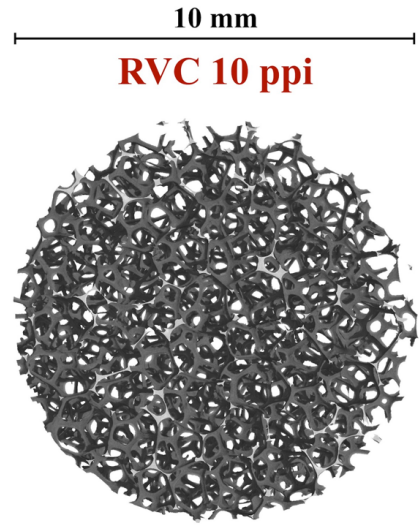

$10 \mathrm{~mm}$

RVC 45 ppi
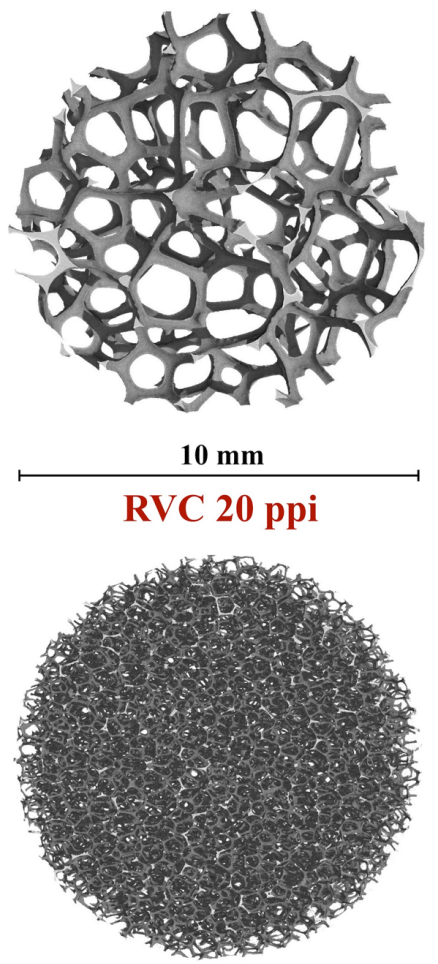

$10 \mathrm{~mm}$

RVC 80 ppi
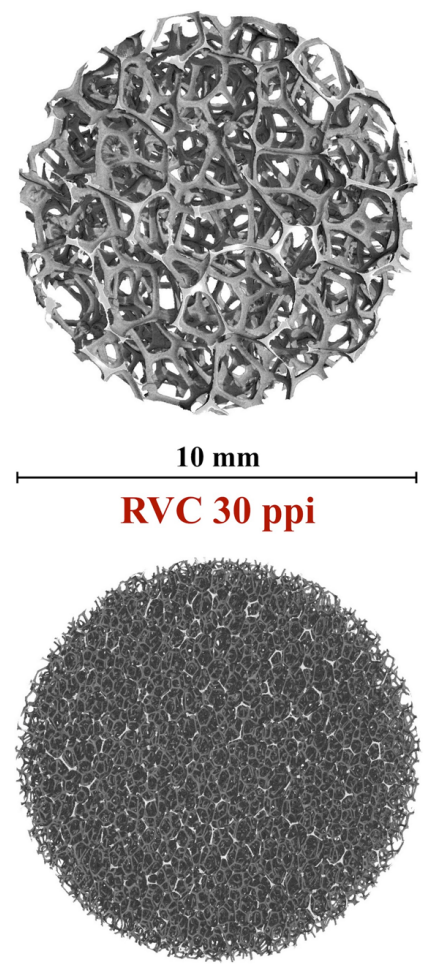

$10 \mathrm{~mm}$

RVC 100 ppi

Figure 6. Top view of 3D-rendered CT scans of uncoated RVC samples, showing various ppi grades. The surface area to volume ratio increases with porosity grade.

Table 1 shows characteristics of the ROI volumes considered for the dimensional study of RVC as provided by VG Studio MAX algorithm. The effect of porosity grade on the volumetric porosity, $\varepsilon$, is negligible, with an average value of 0.966 from the $\mu \mathrm{CT}$ scans here presented and in close agreement with the manufacturer's data, nominally 0.97 . This is not surprising, since commercial RVC is usually manufactured so that its porosity and relative density are similar across the range of ppi grades. Similarly, the tortuosity of RVC is approximately constant at 1.02 regardless of the number of ppi [11]. 
Table 1. Volumetric porosity of RVC as function of nominal porosity grade.

Estimated from $\mu \mathrm{CT}$ data at a resolution of $9.6 \mu \mathrm{m}$ per voxel.

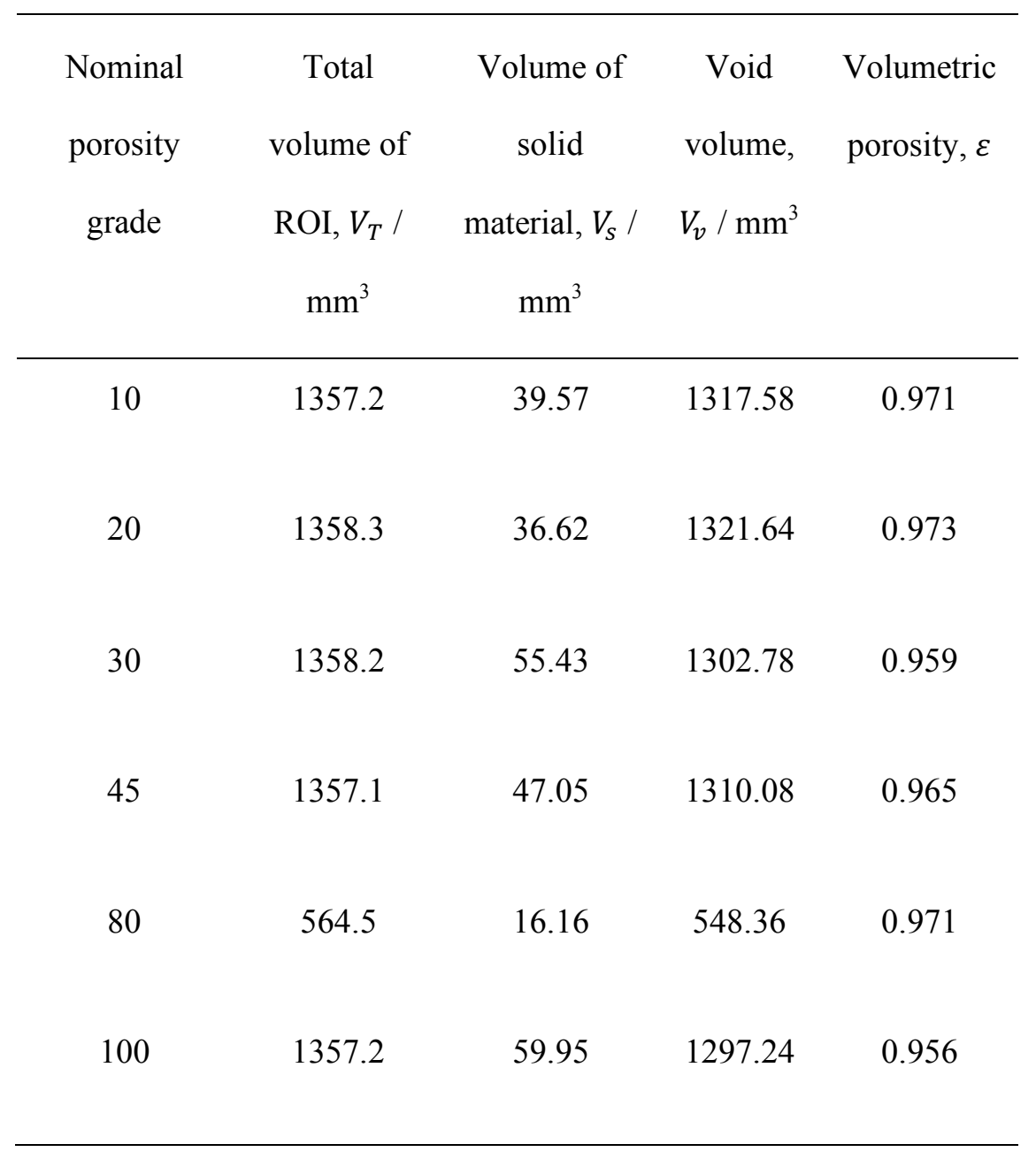

The porosity of RVC was also estimated from the ratio between occupied area by solid material at the 2D surface delimiting the cylindrical ROIs and the total external surface area of the cylinders. These characteristics and the resulting surface porosity, $\varepsilon_{s}$, of RVC are given in Table 2. In all cases, $\varepsilon_{s}$ values are similar to those calculated from the occupied volume, although slightly superior. As in the previous case, $\varepsilon_{s}$ does not change significantly as a function of ppi grade, the average value for all specimens being 0.971 . 2D cross-sections of the various RVC grades are shown in Figure 7 to illustrate the highly permeable, low density nature of the RVC structure. The openfoam cells are interconnected by large windows, and only cross-sections of the struts 
are visible. In contrast, unit cells in closed-foams have the appearance of 'bubbles' like in, e.g., aluminium foams [36].

Table 2. Surface porosity of RVC as function of nominal porosity grade. Estimated from $\mu \mathrm{CT}$ data at a resolution of $9.6 \mu \mathrm{m}$ per voxel.

\begin{tabular}{|c|c|c|c|c|}
\hline Nominal & Total & Area of solid & Void area & Surface \\
\hline porosity & external area & material at ROI & at ROI & porosity, \\
\hline \multirow[t]{2}{*}{ grade } & of ROI, $A_{T} /$ & walls, $A_{S} / \mathrm{mm}^{2}$ & walls, $A_{v} /$ & $\varepsilon_{S}$ \\
\hline & $\mathrm{mm}^{2}$ & & $\mathrm{~mm}^{2}$ & \\
\hline 10 & 678.6 & 16.95 & 661.63 & 0.975 \\
\hline 20 & 678.6 & 16.12 & 662.46 & 0.976 \\
\hline 30 & 678.6 & 24.91 & 655.78 & 0.963 \\
\hline 45 & 678.6 & 22.8 & 405.65 & 0.966 \\
\hline 80 & 414.7 & 9.04 & 654.25 & 0.978 \\
\hline 100 & 678.6 & 24.33 & 653.67 & 0.964 \\
\hline
\end{tabular}



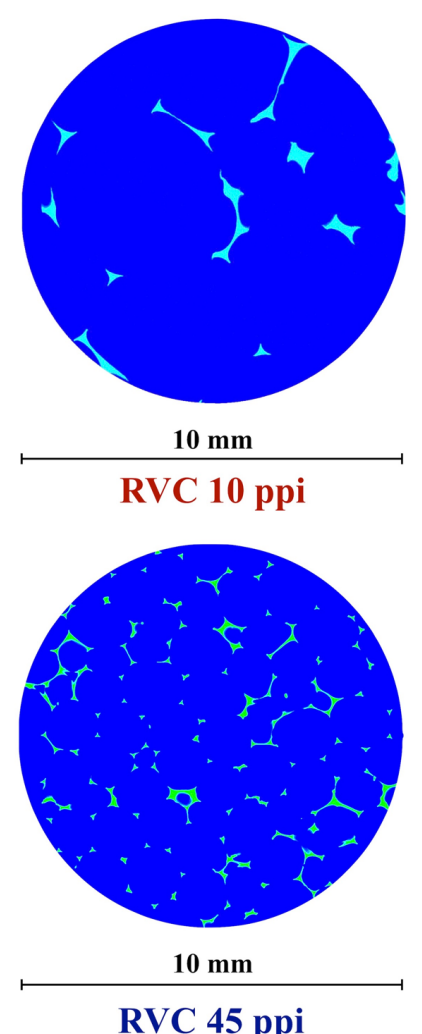

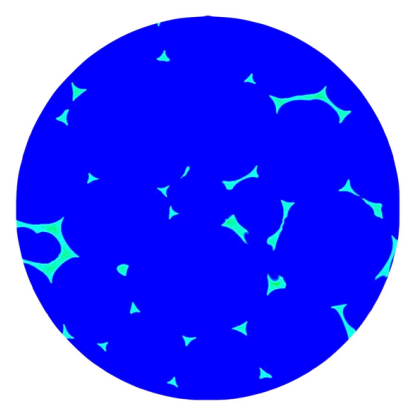

$10 \mathrm{~mm}$

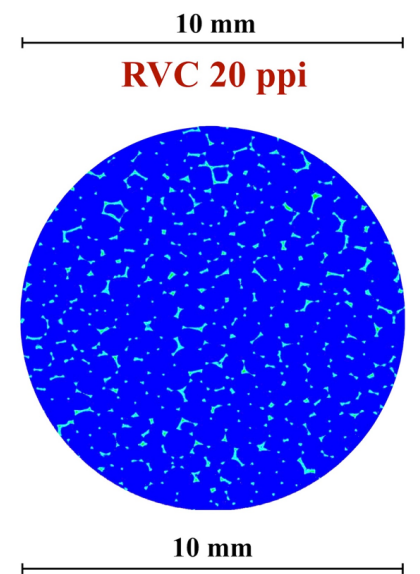

RVC 80 ppi

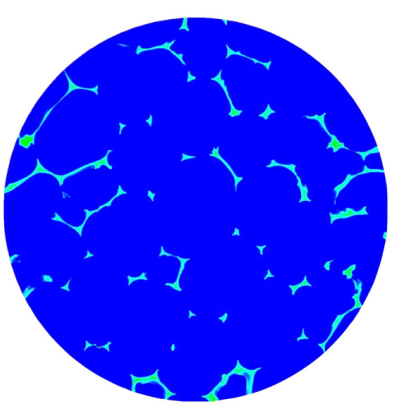

$10 \mathrm{~mm}$

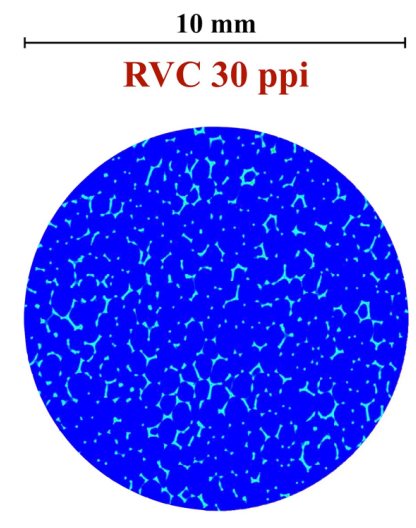

$10 \mathrm{~mm}$

RVC 100 ppi

Figure 7. 2D-orthogonal slices of uncoated RVC $\mu \mathrm{CT}$ images for various porosity grades. Most of the cross-sectional area corresponds to void among the RVC skeleton. Such high volumetric porosity results in equally elevated hydraulic permeability. Solid material appears in bright blue.

\subsection{Estimation of electrical properties from $\mu \mathrm{CT}$ data}

The electrical properties of RVC are relevant to electrochemical applications as they permit to calculate the Ohmic losses along and across an electrode structure. In a foamlike material, such properties are defined by their relative density and cell structure. The latter is given by the ratio between the material's bulk density, $\rho$, to the density of its constituent material, $\rho_{s}$. If the density is isotropic, then:

$$
\frac{\rho}{\rho_{s}}=1-\varepsilon
$$


Regarding structure, the strut cross-section and node volume are especially relevant. In ideal cases, the relative conductivity of foams, $\sigma / \sigma_{s}$, can be modelled as a function of the relative density by [37]:

$$
\frac{\sigma}{\sigma_{s}}=\alpha\left(\rho / \rho_{s}\right)+(1-\alpha)\left(\rho / \rho_{s}\right)^{3 / 2}
$$

where $\sigma$ is the conductivity of the foam, $\sigma_{s}$ is the conductivity of the solid, and $\alpha$ is a constant describing the distribution of material between struts and nodes. In open-cell foams, such as RVC, $\alpha$ approaches 0.33 . Although the bulk electrical resistivity, $\theta$, can readily be derived from the previous expression, it can also be approximated through a simple empirical model from the resistivity of the solid material, $\theta_{S}[37]$ :

$$
\theta \approx \theta_{s}\left(\rho / \rho_{s}\right)^{-r}
$$

where $r$ has values between 1.6 and 1.85 depending on the type of foam structure.

In order to obtain conductivity and resistivity from $\mu \mathrm{CT}$ data, the relative density of RVC was calculated using equation (3) from the volumetric porosity obtained at a resolution of $9.6 \mu \mathrm{m}$ per voxel. This was, in turn, used to calculate the relative conductivity as well as the bulk conductivity and resistivity via equation (4). A value of $\sigma_{s}=181 \mathrm{~S} \mathrm{~cm}^{-1}\left(\theta_{s}=5.5 \times 10^{-3} \Omega \mathrm{cm}\right)$ at $25^{\circ} \mathrm{C}$ was considered, which is an average 
value from those reported by some vitreous carbon suppliers. ${ }^{3,4}$ RVC's bulk resistivity was also estimated from equation (5), where $r$ was arbitrarily set to 1.7 as it approached the results of equation (4). The values are presented in Table 3.

Table 3. Relative density and related electrical properties of RVC calculated from the volumetric porosity obtained from $\mu \mathrm{CT}$ scans at a resolution of $9.6 \mu \mathrm{m}$ per voxel.

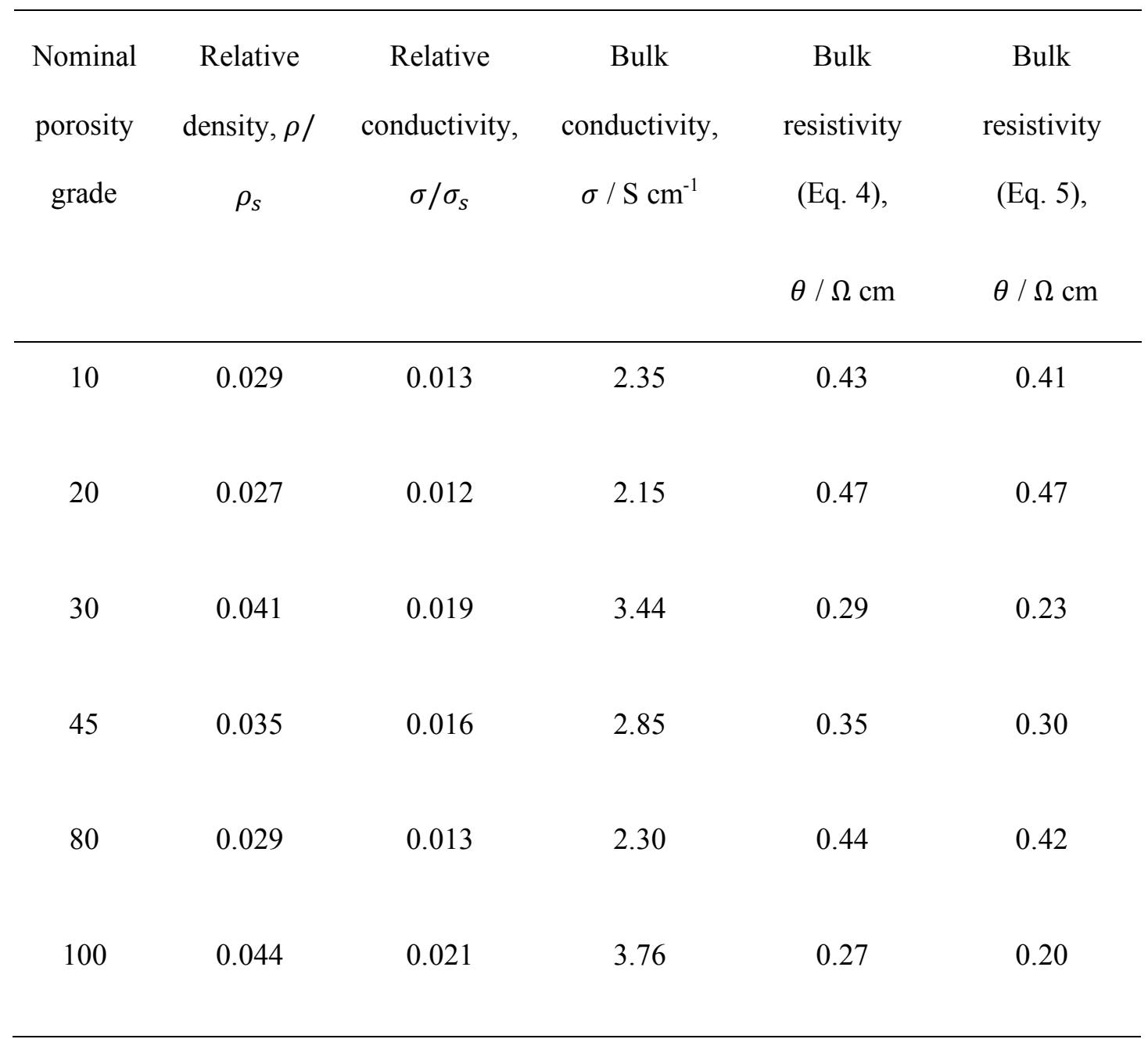

\footnotetext{
${ }^{3}$ MWI Inc., Typical properties of glassy carbon, www.mwi-inc.com/wpcontent/uploads/2014/10/PropGlassyCarbon.pdf (accessed 2 Feb., 2018)

${ }^{4}$ SPI Supplies, Glassy carbon product information, https://www.2spi.com/catalog/documents/GlassyVitreous-Carbon-Info.pdf (accessed 2 Feb., 2018)
} 
Relative density had similar values for all RVC grades and, as a result, the calculated electrical properties do not show any clear relationship to porosity, especially considering that only one $\mu \mathrm{CT}$ scan could be performed for each grade. The bulk resistivity calculated from equation (4) falls between $0.27 \Omega \mathrm{cm}$ and $0.47 \Omega \mathrm{cm}$. Equation (5) gives consistent results but yields slightly lower values as the ppi number increases.

These results show good agreement with the average nominal value given by the supplier for all ppi grades, $0.32 \Omega \mathrm{cm} .^{5}$ A close range of bulk resistivity between 0.47 $\Omega \mathrm{cm}$ and $0.69 \Omega \mathrm{cm}$ was described by Wang et al. for a slightly less conductive RVC [2]. More recent experimental values for in-house prepared (polyurethane-based) RVCs are also close. For instance, Harikrishnan et al. [38] reported $0.48 \Omega \mathrm{cm}$ for RVC 26 ppi decreasing to $0.22 \Omega \mathrm{cm}$ for RVC 78 ppi. Similarly, the RVC prepared by Smorygo et al. [39], showed a resistivity between $0.25 \Omega \mathrm{cm}$ and $0.08 \Omega \mathrm{cm}$ depending on the bulk density. Gonçalves et al. [40] provided values below $1.0 \Omega \mathrm{cm}$ for RVC treated at temperatures over $1000{ }^{\circ} \mathrm{C}$. In contrast, a different material such as tannin-based cellular vitreous carbon (CVC), displays a resistivity nearly an order of magnitude lower; between $7.69 \Omega \mathrm{cm}$ to $4.16 \Omega \mathrm{cm}$ for porosities between $83 \%$ and $98 \%$ [41].

In summary, $\mu \mathrm{CT}$ rendered RVC structures have proved to be useful in the calculation of electrical resistivity values from their estimated volumetric porosities in agreement with available data. Direct comparisons between $\mu \mathrm{CT}$-derived values and experimental

\footnotetext{
${ }^{5}$ ERG Materials and Aerospace Co., Reticulated vitreous carbon, Ergaerospace.com, http://ergaerospace.com/technical-data/surface-area-of-duocel-foam (accessed Mar. 21, 2018).
} 
values could be performed by measuring RVC's resistivity in a modified four-point probe set up, such as the one described in [42].

\subsection{Volumetric surface area of RVC}

The performance of RVC in electrochemical flow cells is directly dependent on its volumetric surface area, $A_{e}$, and on the mass transport coefficient developed by electrolyte flow through the porous structure, $k_{m}$. The product of these terms is an electrode performance factor called the volumetric mass transport coefficient, $k_{m} A_{e}$ [43]. For diluted electrolytes, high RVC grades yield better performance due to their larger active electrode areas. For instance, $k_{m} A_{e}$, for RVC 100 ppi is approximately an order of magnitude superior to RVC 10 ppi for the removal of $\mathrm{Cu}$ (II) ions [3]. Furthermore, the electrochemical-hydraulic performance of different RVC grades can be assessed by plotting $k_{m} A_{e}$ as a function of linear flow velocity [3,44] or the associated pressure drop [45]. Analogous expressions are available for heat exchangers, i.e., heat dissipation index vs. pressure drop [37]. Finally, $A_{e}$ allows calculating the current density (and current distribution) at which electron transfer reactions take place.

Automatic and semi-automatic analysis of rendered $3 \mathrm{D}$ reconstructions of $\mu \mathrm{CT}$ scans offers a convenient method for measuring the volumetric surface area, $A_{e}$, of porous materials, provided that an appropriate voxel resolution is employed. This has been enabled by advances in $\mu \mathrm{CT}$ technology and computational power. In almost two decades following Ashby's et al. book on metal foams [37], the resolution of industrial CT has increased from $200 \mu \mathrm{m}$ per voxel to typically less than $1 \mu \mathrm{m}$ per voxel, not to mention advances in post-processing functions and algorithms. In contrast, other 
techniques such as synchrotron radiation computed tomography (SRCT) and X-ray computerized nano-tomography (nano-CT) might be less accessible or inconvenient for most studies of macroscopic foams. SRCT would still be adequate when there is requirement for high throughput, but expense and lead time can be problematic. On the other hand, nano-CT could provide extremely high resolution, but even simple scans would take days using current technology.

The study of RVC's volumetric surface area by $\mu \mathrm{CT}$ has not been reported, although the cell size of a tannin-based RVC specimen was recently measured by this technique [46]. (Studies of metal deposit distribution on RVC substrates using radiography [47] and low-resolution CT [48] are available.) However, scanning conditions must be first established for maximum accuracy. This means selecting a voxel resolution and thresholding method that results in an impartial and repeatable segmentation of the cells $[25,49]$. As a first approach, the volumetric surface area of the various RVC grades is presented in Table 4 as obtained at a resolution of $9.6 \mu \mathrm{m}$ per voxel for exposures times of $1 \mathrm{~s}$ and a field of view over $19 \mathrm{~mm}$ with a Nikon/X-Tek XTH 225 instrument. Surface area was estimated from non-binarized data employing the ISO50\% threshold. An error value was established by manually shifting the threshold in the histogram by $25 \%$ towards the peak of RVC. $A_{e}$ is then calculated by dividing the total area of RVC by the volume of the ROI given in Table 1. 
Table 4. Volumetric surface area, $A_{e}$, of RVC from $\mu \mathrm{CT}$ scans performed at a resolution of $9.6 \mu \mathrm{m}$ per voxel.

\begin{tabular}{|c|c|c|}
\hline Nominal & Total ISO50\% & Volumetric \\
\hline porosity & area of RVC, & surface area, \\
\hline grade & $A_{R V C} / \mathrm{mm}^{2}$ & $A_{e} / \mathrm{cm}^{-1}$ \\
\hline 10 & $912.8 \pm 2.3$ & $6.73 \pm 0.02$ \\
\hline 20 & $1131.8 \pm 5.7$ & $8.33 \pm 0.04$ \\
\hline 30 & $2359.3 \pm 91.4$ & $17.37 \pm 0.67$ \\
\hline 45 & $2381.3 \pm 109.7$ & $17.54 \pm 0.81$ \\
\hline 80 & $1552.4 \pm 176.3$ & $27.50 \pm 3.12$ \\
\hline 100 & $5878.3 \pm 590.0$ & $43.31 \pm 4.35$ \\
\hline
\end{tabular}

As shown in Figure $8, A_{e}$ appears to be underestimated, at this resolution, when compared against previous work on pressure drop data via the Ergun equation [3] and geometrical measurements in SEM images [22], which were consistent with manufacturers' data from a unspecified method. ${ }^{6}$ For 100 ppi RVC, the $\mu \mathrm{CT}$ unit area per volume represents $64 \%$ of the value given by SEM. A linear tendency can be observed, the divergence from well-established findings appears to be proportional to the number of ppi. The main cause of the inaccuracy is edge detection issues between the carbon material and air due to a relatively large voxel size and the consequent effect

\footnotetext{
${ }^{6}$ ERG Materials and Aerospace Co., Reticulated vitreous carbon, Ergaerospace.com, http://ergaerospace.com/technical-data/surface-area-of-duocel-foam (accessed Mar. 21, 2018).
} 
on the surface boundary determination. This means that more accurate values of $A_{e}$ necessitate higher spatial resolution, a narrower field of view and significantly longer exposure times relative to a lower-resolution scan.

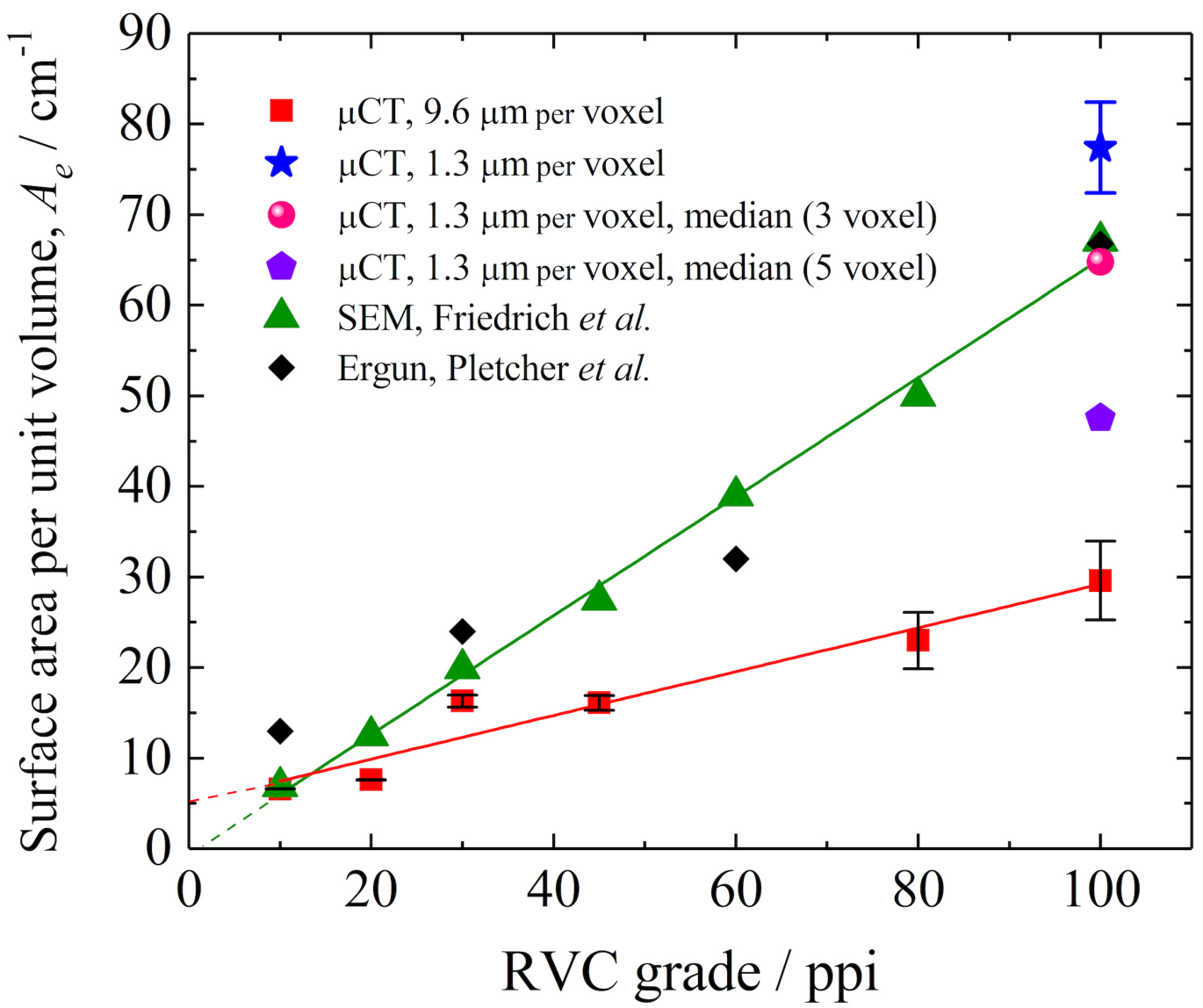

Figure 8. Surface area per unit volume of different RVC grades. $\mu \mathrm{CT}$ data for all specimens obtained at a resolution of $9.6 \mu \mathrm{m}$ per voxel, and additionally for RVC 100 ppi at $1.3 \mu \mathrm{m}$ per voxel. Comparative data from SEM measurements [1,22] and pressure drop via the Ergun equation [3]. Linear fit for Friedrich's $A_{e}$ SEM data: $y=0.66 x-0.53\left(\mathrm{R}^{2}=0.99\right)$. Linear fit for (underestimated) $A_{e}$ by $\mu \mathrm{CT}$ at low resolution: $y=0.11 x+5.44\left(\mathrm{R}^{2}=0.78\right)$. 
Aiming to find the conditions for obtaining accurate surface area data, we performed a single high-resolution scan for RVC 100 ppi in a Zeiss Xradia 510 Versa X-ray microscope, in this instance with an exposure time of 12 seconds per projection and a field of view of $2.7 \mathrm{~mm}$, which was determined by scintillator size. This produced a resolution of $1.3 \mu \mathrm{m}$ per voxel. The resulting $100 \mathrm{ppi} \mathrm{RVC}$ rendered structure is shown in Figure 9a). This $\mu \mathrm{CT}$ displayed what appears to be void micro-pores within the struts and nodes of RVC; this is also seen in Figure 2a). However, these features are not observed in SEM images of the same material; a typical example is presented in Figure 9d) and a closer view in Figure 9e). Thus, we consider these 'apparent micro-pores' to be artifacts in the $\mu \mathrm{CT}$ scan, perhaps induced by local low-density heterogeneities in the material in combination with the employed thresholding method.

Still, an average surface area and an error interval were estimated for the raw structure in Figure 9a) by visually setting the threshold at the isosurfaces yielding the maximum and minimum object volume while maintaining the continuity of the external surface of the structure. (Although the histogram showed a clear peak for RVC, a poorly defined peak for air prevented the use of ISO50\% thresholding.) The resulting volumetric and surface area characteristics of this structure are presented in Table 5. As shown in Figure 8, the average surface area from visual thresholding yielded values $c a$. $23 \%$ higher to those obtained from SEM [1,22] and pressure drop [3] measurements. Such a large discrepancy for a raw, unprocessed $\mu \mathrm{CT}$ rendering is not unexpected, since the artifacts resembling micro-pores contribute to the digital value of $A_{e}$, something not occurring in physical measurements dependent on either the visible external surface, as in SEM measurements, or the surface in contact with a fluid. 

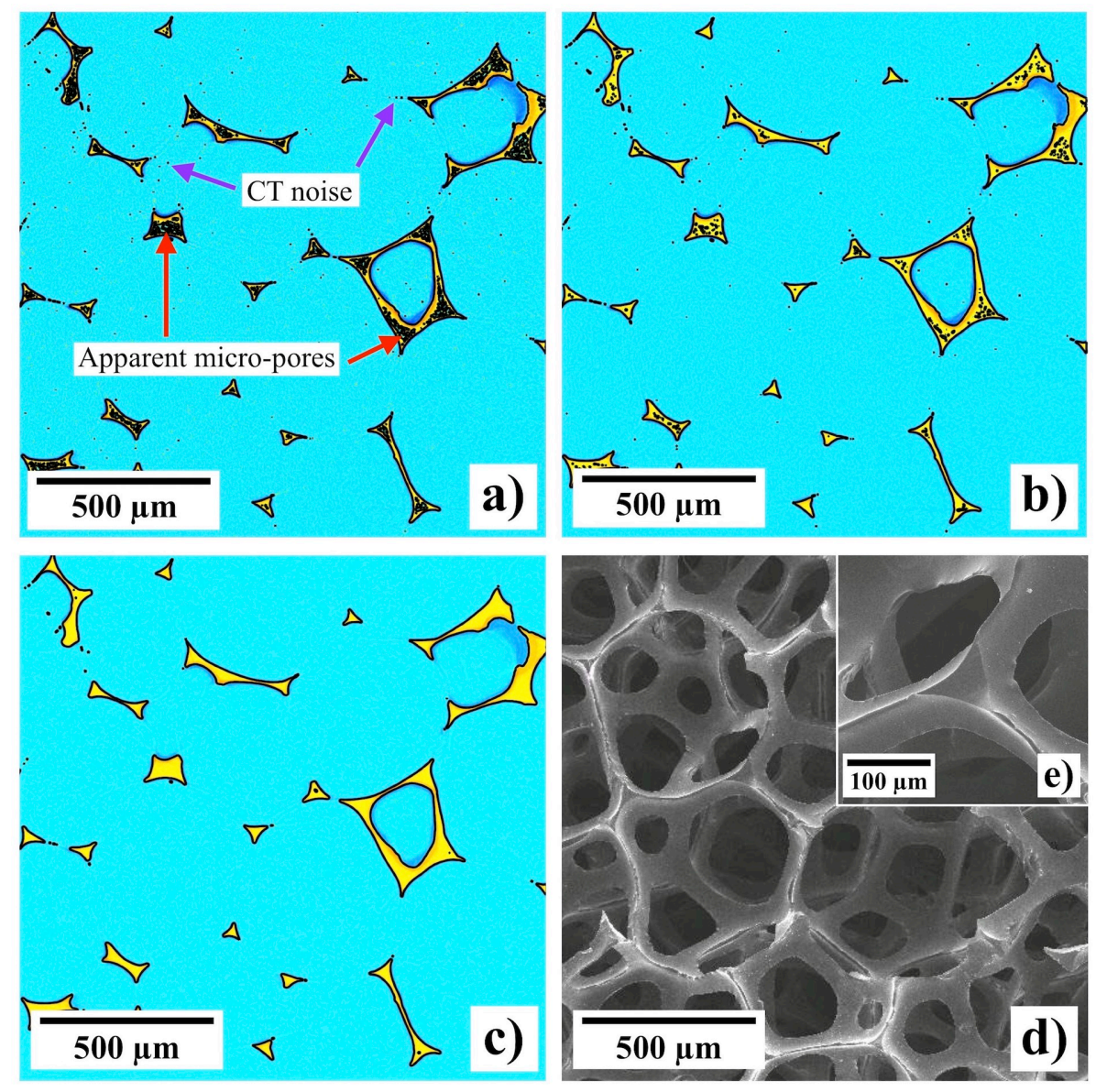

Figure 9. a) Apparent micro-porosity and noise in a section of 100 ppi RVC as shown by a $\mu \mathrm{CT}$ scan at a resolution of $1.3 \mu \mathrm{m}$ per voxel. b) The same structure filtered by a median function applied to groups of 3 voxels. c) A homogeneous 'solid' rendered structure obtained by applying the median function to groups of 5 voxels. d) SEM image of 100 ppi RVC. e) Closer view of a typical strut cross-section in the same material; apparent micropores are not observed.

In order to estimate the total surface area of RVC constituted by a homogenous carbon material (free of apparent micro-pore artifacts), a filtering median function was applied to the raw data in VG Studio MAX. The filter parameters were set to clusters of first 3 voxels and then 5 voxels. Their characteristics are given in Table 5 . The value of $A_{e}$ 
for the filtered 100 ppi RVC structure (3 voxels), shown in Figure 9b), is consistent with that produced by SEM and pressure drop, although it must be noted that the micropore artefacts were not eliminated entirely. The median-filtered 100 ppi RVC structure (5 voxels), shown in Figure 9c), is in effect a homogenous, 'solid' material, similar to real RVC. As shown in Figure 8, this $A_{e}$ is $c a .47 .5 \mathrm{~cm}^{-1}$, which represents $71 \%$ of that reported by Friedrich et al. This discrepancy could suggest that the geometrical surface area of RVC is more limited than that given by SEM and pressure drop. However, given the dependence of the surface area on the filter settings and their effect on the threshold boundary, together with the agreement between SEM and pressure drop, we are more inclined to conclude that the digital structure in Figure 9c) has an artificially low surface area.

Additional post-processing on the RVC rendered structure and the study of multiple samples (and ppi grades) are needed to resolve this question unequivocally. After going through a noise reduction filter, a more sophisticated thresholding algorithm should be applied [50]. The projections could then be binarized and the pore-like artifacts removed by a filling function so that only the wall surface area is subjected to quantitative analysis. 
Table 5. Characteristics of 100 ppi RVC from a $\mu \mathrm{CT}$ scan with a resolution $1.3 \mu \mathrm{m}$ per voxel. Dimensions of ROI: $2.66 \mathrm{~mm}$ diameter, $2.72 \mathrm{~mm}$ height and a total volume of $15.12 \mathrm{~mm}^{3}$.

\begin{tabular}{|c|c|c|c|c|c|}
\hline Thresholding & $\begin{array}{c}\text { Volume of } \\
\text { solid material, } \\
V_{S} / \mathrm{mm}^{3}\end{array}$ & $\begin{array}{c}\text { Void } \\
\text { volume, } \\
V_{v} / \mathrm{mm}^{3}\end{array}$ & $\begin{array}{l}\text { Volumet } \\
\text { ric } \\
\text { porosity, } \\
\qquad \varepsilon\end{array}$ & $\begin{array}{c}\text { Total } \\
\text { surface area } \\
\text { of RVC, } \\
A_{R V C} / \mathrm{mm}^{2}\end{array}$ & $\begin{array}{c}\text { Volumetri } \\
\text { c surface } \\
\text { area, } A_{e} / \\
\mathrm{cm}^{-1}\end{array}$ \\
\hline $\begin{array}{c}\text { Visual on raw } \\
\text { data }\end{array}$ & $0.30 \pm 0.07$ & $\begin{array}{c}14.82 \pm \\
0.07\end{array}$ & $\begin{array}{c}0.980 \pm \\
0.005\end{array}$ & $117.0 \pm 7.6$ & $77.4 \pm 5.0$ \\
\hline $\begin{array}{c}\text { Median } \\
\text { filtered, } 3 \\
\text { voxels }\end{array}$ & 0.52 & 14.60 & 0.966 & 97.9 & 64.8 \\
\hline $\begin{array}{c}\text { Median } \\
\text { filtered, } 5 \\
\text { voxels }\end{array}$ & 0.53 & 14.59 & 0.965 & 71.8 & 47.5 \\
\hline
\end{tabular}

Still, a resolution of $1.3 \mu \mathrm{m}$ per voxel has proved to possess the detail level required to resolve the features of the material for surface area measurements. Indeed, it has been pointed out that a resolution of $5.0 \mu \mathrm{m}$ per voxel was adequate for the study of cell sizes in many types of carbon foams [46], but insufficient for resolving their cell walls. Resolutions under $1.5 \mu \mathrm{m}$ per voxel have been preferred for the resolution of features in carbon felts [51], and others have employed resolutions of $2.44 \mu \mathrm{m}$ per voxel for the study of carbon paper [52]. These comparisons reinforce the necessity for resolutions of at least $1.3 \mu \mathrm{m}$ per voxel in the study of RVC's volumetric surface area. 
It is worth commenting on the collection of $A_{e}$ data from $\mu \mathrm{CT}$ against other methodologies. For macroporous, single phase foam-like materials, a well-equipped $\mu \mathrm{CT}$ facility is able to perform scans with little specimen preparation and quickly extract quantitative structural data aided by dedicated software tools. With an appropriate resolution, the data can be extremely accurate. However, specimen sizes and number of scans are restrictive in $\mu \mathrm{CT}$. In contrast, surface area measurements on SEM images, such as $[1,22]$, are time consuming and tedious, although it is possible to obtain accurate $A_{e}$ data at relatively low cost. The SEM method is faster and more convenient for the study of cell size distribution when compared to $\mu \mathrm{CT}$ [46]. Close estimations of $A_{e}$ and tortuosity from pressure drop measurements via the Ergun equation (given $\varepsilon$ ) benefit from simplicity and low cost, allowing to determine such characteristics for much larger specimens with the aid of a fluid [53,54]. A known disadvantage is that large errors can appear when the pressure drop is small [3].

The measurement of a 'true' $A_{e}$ depends on the level of surface features considered and is therefore, highly relative and dependent on the methodology. For instance, Brunauer, Emmett and Teller gas adsorption method (BET) appears to overestimate $A_{e}$ values of RVC-like foams, as it takes on account the adsorption on the carbonaceous surface [53]. These effects are well-known in electrochemistry [55], where different methods are employed in diverse situations. Perhaps an alternative and seemingly convenient methodology for electrochemical flow cells consists in the determination of the critical superficial flow velocity from reactant conversion $v s$. mean linear flow velocity plots [56], since it estimates the effective electrochemical area of a porous material in these conditions. 


\subsection{Cell volume and cell surface dispersion of RVC $100 \mathrm{ppi}$}

A characterization of cell volume and cell surface dispersion was performed on RVC 100 ppi from the ROI acquired at high resolution employing Avizo 9.1. The raw data was resampled to a resolution of $6 \mu \mathrm{m}$ per voxel in order to reduce computational processing time. A threshold and a close-hole function was then applied to the rendered structure. After running the cell analysis, noise was removed by excluding 366 micropores with less than 27 voxels of volume $\left(27 \times 6^{3} \mu \mathrm{m}^{3}\right)$ and 4 objects with more than $1.5 \times 10^{8} \mu \mathrm{m}^{3}$ of volume corresponding to fused broken cells at the borders of the ROI.

The resulting distributions of cell volume and cell surface area are shown in Figure 10. For cell volume, $\bar{x}=6.5 \times 10^{7}\left(\mathrm{SD}=3.2 \times 10^{7}\right)$ and for surface area $\bar{x}=9.4 \times 10^{5}(\mathrm{SD}$ $=3.5 \times 10^{5}$ ). They display, however, a closer fit to a gamma curve rather than to a normal one, in accordance to calculations on random Laguerre tessellations obtained from reconstructed closed foams through CT analysis [31]. If the individual cells are assumed to be spherical volumes, then the average pore diameter, $d_{p}$, for RVC 100 ppi is $249 \mu \mathrm{m}$. This value is practically the same as that reported by Reade et al. from SEM images [1,57], although Friedrich et al. reported an average of $175 \mu \mathrm{m}$ [12]. Similarly, by naively assuming an arrangement of regular dodecahedral cells, the average area of each pentagonal (strut-less) face can be thought to be about $7.8 \times 10^{4} \mu \mathrm{m}^{2}$ and thus contrasted to the average window area of $3.1 \times 10^{4} \mu \mathrm{m}^{2}$ reported by the same author for 100 ppi RVC. The values are comparable, but their difference confirms that only a combination of complex 3D structures of different sizes is analogous to the real material; see [58]. 


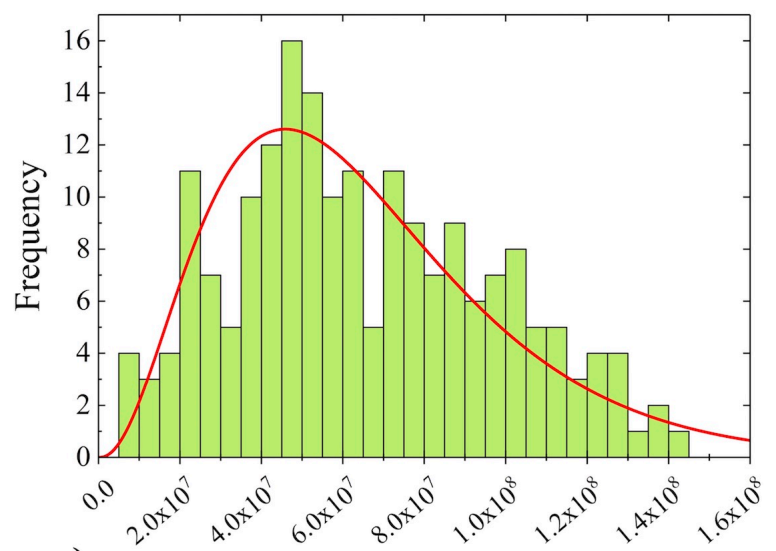

a)

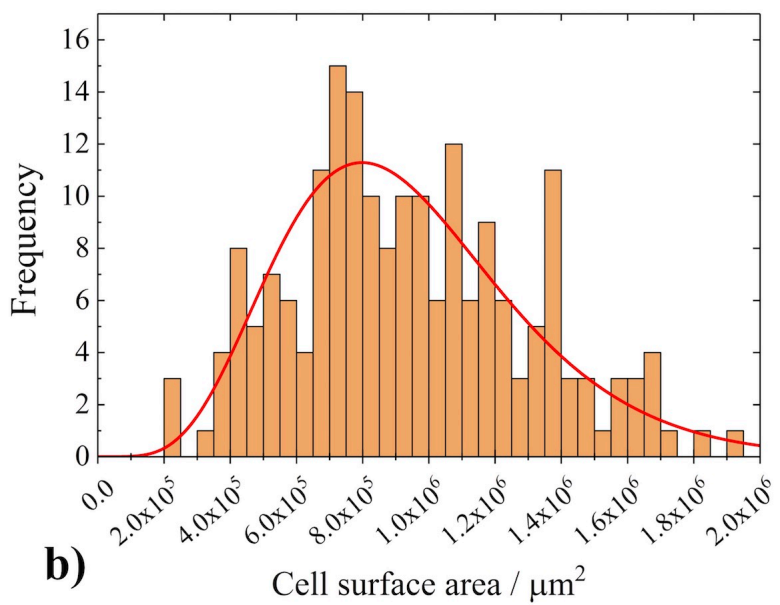

Cell surface area $/ \mu \mathrm{m}^{2}$

Figure 10. Distribution of the open-foam cell properties in 100 ppi RVC at a resampled resolution of $6 \mu \mathrm{m}$ per voxel from a $\mu \mathrm{CT}$ scan: a) cell volume b) cell surface area. Both approximate to gamma distributions.

\section{Conclusions}

We have shown that high resolution $\mu \mathrm{CT}$ in the order of $1.3 \mu \mathrm{m}$ per voxel is necessary when determining the volumetric surface area of RVC in agreement with $2 \mathrm{D}$ imaging and experimental data, although suitable post-processing methods and multiple samples are needed in order to produce reliable data. At lower resolutions, the surface area of this open carbon foam is underestimated, an effect that is magnified as a function of the number of ppi. On the other hand, volumetric porosity, superficial porosity and relative density can be estimated satisfactorily by using resolutions of $9.6 \mu \mathrm{m}$ per voxel. This was confirmed by calculating the resistivity of bulk RVC and showing its agreement with values reported in the literature. Cell volume and cell surface dispersion for RVC 100 ppi are approximated by gamma distributions and a related calculated average pore size was consistent with previous SEM measurements. The cost and time needed for $\mu \mathrm{CT}$ scans can be justified by the imaging and analysis of porosity and surface areas in 
macroporous solid foams, although the study of cell size distribution is sometimes more convenient by SEM imaging. The typical 3D structure of RVC can now be digitized and made available at different resolutions for computer modelling in various fields, such as electrochemical, thermal, electrical and fluid flow simulations, opening new areas of study.

\section{Recommendations and future work}

Future work will focus in the acquisition of high-resolution $\mu \mathrm{CT}$ surface area for all RVC grades and further discussion on the establishment of their 'true' values. More work on image post-processing and thresholding is needed in order to improve or validate the available data. By performing scans on a range of porosity grades at various spatial resolutions, a 'phase diagram' could be created to find a compromise between accuracy and field-of-view for each ppi grade. A mathematical model could then be developed to calculate minimum acceptable resolution as a function of ppi. Phase edge effects on $\mu \mathrm{CT}$ scans for this type of porous materials could be considered as well.

High-resolution $\mu \mathrm{CT}$ and nano-CT are expected to be suitable techniques for the study of several recently introduced hierarchical RVC-based active materials, such as 'hairy foams' $[35,59,60]$. Such materials enhance the active surface area and functionality of the substrate by growing or binding nanotubes onto the struts, or by placing felts or webs in the voids inside pores. Possible applications of nano-CT on RVC include microbial fuel cells [35,60], wettability control [61], and supercapacitors [62].

\section{Acknowledgements}

LFA is grateful to the Research Institute for Industry of the University of Southampton 
for provision of materials and additional funding. The tomographic imaging facilities in the $\mu$-VIS centre at the University of Southampton are supported by EPSRC grant EP-H01506X, 2009.

\section{Nomenclature}

$A_{e} \quad$ Volumetric surface area, $\mathrm{cm}^{-1}$

$k_{m} \quad$ Mass transport coefficient, $\mathrm{cm} \mathrm{s}^{-1}$

$k_{m} A_{e}$ Volumetric mass transport coefficient, $\mathrm{s}^{-1}$

$L \quad$ Length of a flow channel containing a porous material, $\mathrm{cm}$

$M \quad$ Ergun's empirical constant for turbulent forces, $\mathrm{Pa} \mathrm{s}^{2} \mathrm{~m}^{-3}$

$N \quad$ Ergun's empirical constant for inertial forces, $\mathrm{Pa} \mathrm{s} \mathrm{m}^{-2}$

$r \quad$ Constant in equation (5), dimensionless

$v \quad$ Mean linear velocity of a fluid, $\mathrm{cm} \mathrm{s}^{-1}$

$\alpha \quad$ Constant in equation (4), dimensionless

$\gamma \quad$ Circularity factor of a pore, dimensionless

$\varepsilon \quad$ Volumetric porosity, dimensionless

$\varepsilon_{s} \quad$ Surface porosity, dimensionless

$\theta \quad$ Bulk electrical resistivity of the foam, $\Omega \mathrm{cm}$

$\theta_{s} \quad$ Electrical resistivity of the solid material, $\Omega \mathrm{cm}$

$\rho \quad$ Bulk density of the foam, $\mathrm{g} \mathrm{cm}^{-3}$

$\rho_{s} \quad$ Density of the solid material, $\mathrm{g} \mathrm{cm}^{-3}$

$\tilde{\rho} \quad$ Density of a fluid, $\mathrm{g} \mathrm{cm}^{-3}$

$\sigma \quad$ Bulk electrical conductivity of the foam, $\mathrm{S} \mathrm{cm}^{-1}$

$\sigma_{s} \quad$ Electrical conductivity of the solid material, $\mathrm{S} \mathrm{cm}^{-1}$ 


\section{References}

[1] F.C. Walsh, L.F. Arenas, C. Ponce de León, G.W. Reade, I. Whyte, B.G. Mellor, The continued development of reticulated vitreous carbon as a versatile electrode material: Structure, properties and applications, Electrochim. Acta. 215 (2016) 566-591.

[2] J. Wang, Reticulated vitreous carbon - a new versatile electrode material, Electrochim. Acta. 26 (1981) 1721-1726.

[3] D. Pletcher, I. Whyte, F.C. Walsh, J.P. Millington, Reticulated vitreous carbon cathodes for metal ion removal from process streams part I: Mass transport studies, J. Appl. Electrochem. 21 (1991) 659-666.

[4] F. Rodriguez-Valadez, C. Ortiz-Éxiga, J.G. Ibanez, A. Alatorre-Ordaz, S. Gutierrez-Granados, Electroreduction of $\mathrm{Cr}(\mathrm{VI})$ to $\mathrm{Cr}(\mathrm{III})$ on reticulated vitreous carbon electrodes in a parallel-plate reactor with recirculation, Environ. Sci. Technol. 39 (2005) 1875-1879.

[5] Y.A. Bustos, J.G. Rangel-Peraza, M.N. Rojas-Valencia, E.R. Bandala, A. Álvarez-Gallegos, L. Vargas-Estrada, Treatment of industrial effluents by electrochemical generation of $\mathrm{H}_{2} \mathrm{O}_{2}$ using an RVC cathode in a parallel plate reactor, Environ Technol. (2015).

[6] I. Ruggeri, C. Arbizzani, F. Soavi, A novel concept of semi-solid, Li redox flow air $\left(\mathrm{O}_{2}\right)$ battery: a breakthrough towards high energy and power batteries, Electrochim. Acta. 206 (2016) 291-300. 
[7] M. Letellier, C. Delgado-Sanchez, M. Khelifa, V. Fierro, A. Celzard, Mechanical properties of model vitreous carbon foams, Carbon. 116 (2017) $562-571$.

[8] M. Łukaszewski, A. Żurowski, A. Czerwiński, Hydrogen in thin Pd-based layers deposited on reticulated vitreous carbon-A new system for electrochemical capacitors, J. Power Sources. 185 (2008) 1598-1604.

[9] A. Czerwiński, Z. Rogulski, S. Obrębowski, H. Siwek, I. Paleska, M. Chotkowski, et al., RVC as new carbon material for batteries, 39 (2009) 559567.

[10] N.C. Gallego, J.W. Klett, Carbon foams for thermal management, Carbon. 41 (2003) 1461-1466.

[11] H.S. Heui-Seol, Characterization of the acoustic properties of random porous media: reticulated vitreous carbon and aluminum foam, J. Korean Phys. Soc. 53 (2008) 607-616.

[12] J.M. Friedrich, Characterisation of electrode materials for electrochemical reactors, University of Southampton, PhD Thesis, 2006.

[13] E. Maire, X-ray tomography applied to the characterization of highly porous materials, Annu. Rev. Mater. Res. 42 (2012) 163-178.

[14] J.-P. Kruth, M. Bartscher, S. Carmignato, R. Schmitt, L. De Chiffre, A. Weckenmann, Computed tomography for dimensional metrology, CIRP Annals. 60 (2011) 821-842.

[15] R. Phelan, D. Weaire, E.A.J.F. Peters, G. Verbist, The conductivity of a foam, J. Phys.: Condens. Matter. 8 (1996) L475-L482. 
[16] S. Youssef, E. Maire, R. Gaertner, Finite element modelling of the actual structure of cellular materials determined by X-ray tomography, Acta Materialia. 53 (2005) 719-730.

[17] P. Ranut, E. Nobile, L. Mancini, High resolution microtomography-based CFD simulation of flow and heat transfer in aluminum metal foams, Applied Thermal Engineering. 69 (2014) 230-240.

[18] S. Das, N.G. Deen, J.A.M. Kuipers, Direct numerical simulation for flow and heat transfer through random open-cell solid foams: Development of an IBM based CFD model, Catalysis Today. 273 (2016) 140-150.

[19] H. Lipson, M. Kurman, Fabricated: The New World of 3D Printing, Wiley, Indianapolis, 2013.

[20] J.A. Meganck, K.M. Kozloff, M.M. Thornton, S.M. Broski, S.A. Goldstein, Beam hardening artifacts in micro-computed tomography scanning can be reduced by X-ray beam filtration and the resulting images can be used to accurately measure BMD, Bone. 45 (2009) 1104-1116.

[21] J.F. Barrett, N. Keat, Artifacts in CT: Recognition and Avoidance, RadioGraphics. 24 (2004) 1679-1691.

[22] J.M. Friedrich, C. Ponce de León, G.W. Reade, F.C. Walsh, Reticulated vitreous carbon as an electrode material, J. Electroanal. Chem. 561 (2004) 203217.

[23] C.S. Vinton, C.H. Franklin, Method for the preparation of carbon structures, US Patent 3,927,186, 1975.

[24] C.S. Vinton, C.H. Franklin, Activated reticulated or unreticulated carbon structures, US Patent 4,154,704, 1979. 
[25] K. Kiekens, F. Welkenhuyzen, Y. Tan, P. Bleys, A. Voet, J.-P. Kruth, et al., A test object with parallel grooves for calibration and accuracy assessment of industrial computed tomography (CT) metrology, Meas. Sci. Technol. 22 (2011) 115502.

[26] R. Phelan, D. Weaire, K. Brakke, Computation of equilibrium foam structures using the surface evolver, Exp. Math. 4 (1995) 181-192.

[27] A. Czerwiński, Z. Rogulski, S. Obrebowski, Positive plate for carbon lead-acid battery, Int. J. Electrochem. Sci. 9 (2014) 4826-4839.

[28] E.G. Klarreich, Foams and honeycombs, American Scientist. 88 (2000) 152161.

[29] A. Inayat, J. Schwerdtfeger, H. Freund, C. Körner, R.F. Singer, W. Schwieger, Periodic open-cell foams: Pressure drop measurements and modeling of an ideal tetrakaidecahedra packing, Chem. Eng. Sci. 66 (2011) 2758-2763.

[30] B. Buffel, F. Desplentere, K. Bracke, I. Verpoest, Modelling open cell-foams based on the Weaire-Phelan unit cell with a minimal surface energy approach, International Journal of Solids and Structures. 51 (2014) 3461-3470.

[31] C. Lautensack, Fitting three-dimensional Laguerre tessellations to foam structures, Journal of Applied Statistics. 35 (2008) 985-995.

[32] Z. Rogulski, M. Chotkowski, A. Czerwiński, Electrochemical behavior of $\mathrm{MnO}_{2} / \mathrm{RVC}$ system, J. New Mat. Electrochem. Systems. 9 (2006) 401-408.

[33] Y. Li, R.J. Ewen, S.A. Campbell, J.R. Smith, Electrochemically controlled release of antischistosomiasis agents from polypyrrole, J. Mater. Chem. 22 (2012) 2687-2694. 
[34] M.A. Méndez, L. Alibabaei, J.J. Concepcion, T.J. Meyer, Electrocatalysis on oxide-stabilized, high-surface area carbon electrodes, ACS Catal. 3 (2013) $1850-1854$.

[35] L. Jourdin, S. Freguia, B.C. Donose, J. Chen, G.G. Wallace, J. Keller, et al., A novel carbon nanotube modified scaffold as an efficient biocathode material for improved microbial electrosynthesis, J. Mater. Chem. A. 2 (2014) 1309313102.

[36] A. Elmoutaouakkil, L. Salvo, E. Maire, G. Peix, 2D and 3D Characterization of Metal Foams Using X-ray Tomography, Advanced Engineering Materials. 4 (2002) 803-807.

[37] M.F. Ashby, A. Evans, N.A. Fleck, L.J. Gibson, J.W. Hutchinson, H.N.G. Wadley, Metal Foams: A Design Guide, Elsevier, 2000.

[38] G. Harikrishnan, T. Umasankar Patro, D.V. Khakhar, Reticulated vitreous carbon from polyurethane foam-clay composites, Carbon. 45 (2007) 531-535.

[39] O. Smorygo, A. Marukovich, V. Mikutski, V. Stathopoulos, S. Hryhoryeu, V. Sadykov, Tailoring properties of reticulated vitreous carbon foams with tunable density, Front. Mater. Sci. 10 (2016) 157-167.

[40] E.S. Gonçalves, M.C. Rezende, M.F.K. Takahashi, N.G. Ferreira, Electrochemical reversibility of reticulated vitreous carbon electrodes heat treated at different carbonization temperatures, Materials Research. 9 (2006) $147-152$.

[41] M. Letellier, J. Macutkevic, P. Kuzhir, J. Banys, V. Fierro, A. Celzard, Electromagnetic properties of model vitreous carbon foams, Carbon. 122 (2017) 217-227. 
[42] A. Kim, M.A. Hasan, S.H. Nahm, S.S. Cho, Evaluation of compressive mechanical properties of Al-foams using electrical conductivity, Composite Structures. 71 (2005) 191-198.

[43] L.F. Arenas, C. Ponce de León, F.C. Walsh, Mass transport and active area of porous $\mathrm{Pt} / \mathrm{Ti}$ electrodes for the $\mathrm{Zn}$-Ce redox flow battery determined from limiting current measurements, Electrochim. Acta. 221 (2016) 154-166.

[44] F.C. Walsh, D. Pletcher, I. Whyte, J.P. Millington, Electrolytic removal of cupric ions from dilute liquors using reticulated vitreous carbon cathodes, J. Chem. Technol. Biotechnol. 55 (1992) 147-155.

[45] L.F. Arenas, C. Ponce de León, F.C. Walsh, Pressure drop through platinized titanium porous electrodes for cerium-based redox flow batteries, AIChE J. 64 (2018) 1135-1146.

[46] M. Letellier, A. Szczurek, M.C. Basso, A. Pizzi, V. Fierro, O. Ferry, et al., Preparation and structural characterisation of model cellular vitreous carbon foams, Carbon. 112 (2017) 208-218.

[47] C.D. Iacovangelo, F.G. Will, Parametric study of zinc deposition on porous carbon in a flowing electrolyte cell, J. Electrochem. Soc. 132 (1985) 851-857.

[48] O.G. Olvera, G.T. Lapidus-Lavine, Use of X-ray tomography for the experimental verification of a mathematical model for the recovery of $\mathrm{Cu}$ and Cd in a flow-by porous electrode reactor, Int. J. Chem. React. Eng. 10 (2012).

[49] P. Iassonov, T. Gebrenegus, M. Tuller, Segmentation of X-ray computed tomography images of porous materials: A crucial step for characterization and quantitative analysis of pore structures, Water Resources Research. 45 (2009) 22. 
[50] J. Glinz, S. Senck, J. Kastner, G. Tondi, Determination of pore size distribution in Tannin- and Lignin-based foams using X-ray microcomputed tomography, in: 8th Conference on Industrial Computed Tomography iCT 2018, Wels, Austria, 2018: pp. 1-7.

[51] G. Qiu, A.S. Joshi, C.R. Dennison, K.W. Knehr, E.C. Kumbur, Y. Sun, 3-D pore-scale resolved model for coupled species/charge/fluid transport in a vanadium redox flow battery, Electrochim. Acta. 64 (2012) 46-64.

[52] Z. Fishman, J. Hinebaugh, A. Bazylak, Microscale tomography investigations of heterogeneous porosity distributions of PEMFC GDLs, J. Electrochem. Soc. 157 (2010) B1643-B1650.

[53] S. Langlois, F. Coeuret, Flow-through and flow-by porous electrodes of nickel foam. I. Material characterization, J. Appl. Electrochem. 19 (1989) 43-50.

[54] J. González-García, P. Bonete, E. Expósito, V. Montiel, A. Aldaz, R. Torregrosa-Maciá, Characterization of a carbon felt electrode: structural and physical properties, J. Mater. Chem. 9 (1999) 419-426.

[55] S. Trasatti, O.A. Petrii, Real surface area measurements in electrochemistry, Pure Appl. Chem. 63 (1991) 711-734.

[56] R.E. Sioda, Criterion of completeness of electrolysis at flow porous electrodes, J. Appl. Electrochem. 8 (1978) 297-304.

[57] G.W. Reade, Mass transport to rotating reticulated vitreous carbon cylinder electrodes, University of Portsmouth, PhD thesis, 1996.

[58] X. Ou, X. Zhang, T. Lowe, R. Blanc, M.N. Rad, Y. Wang, et al., X-ray micro computed tomography characterization of cellular $\mathrm{SiC}$ foams for their applications in chemical engineering, Materials Characterization. 123 (2017) 20-28. 
[59] P.W.A.M. Wenmakers, J. van der Schaaf, B.F.M. Kuster, J.C. Schouten, "Hairy Foam": carbon nanofibers grown on solid carbon foam. A fully accessible, high surface area, graphitic catalyst support, J. Mater. Chem. 18 (2008) 2426-2436.

[60] V. Flexer, J. Chen, B.C. Donose, P. Sherrell, G.G. Wallace, J. Keller, The nanostructure of three-dimensional scaffolds enhances the current density of microbial bioelectrochemical systems, Energy Environ. Sci. 6 (2013) 12911298.

[61] A.K. Karumuri, L. He, S.M. Mukhopadhyay, Tuning the surface wettability of carbon nanotube carpets in multiscale hierarchical solids, Applied Surface Science. 327 (2015) 122-130.

[62] R. Narayanan, H. Vijwani, S.M. Mukhopadhyay, P.R. Bandaru, Electrochemical charge storage in hierarchical carbon manifolds, Carbon. 99 (2016) 267-271. 